\title{
CONCEPCIONES DE PARTICIPACIÓN DE LOS ESTUDIANTES DE DERECHO EN COLOMBIA*
}

\section{CONCEPTS OF PARTICIPATION OF LAW STUDENTS IN COLOMBIA}

\author{
María Teresa Carreño-Bustamante**
}

Fecha de recepción: 11 de noviembre de 2014 Fecha de aceptación: 22 de diciembre de 2014 Disponible en línea: 30 de junio de 2015

\section{Para citar este artículo/To cite this article}

\author{
Carreño-Bustamante, María Teresa, Concepciones de participación de los \\ estudiantes de derecho en Colombia, 130 Vniversitas, 53-90 (2015). http:// \\ dx.doi.org/10.11144/Javeriana.vj130.cped \\ doi:10.11144/Javeriana.vj130.cped
}

* El presente artículo trata la participación como utopía, uno de los aspectos más relevantes de Concepciones de participación de los estudiantes de derecho en Colombia, investigación terminada por la autora en agosto de 2012 y elaborada como requisito de grado para optar el título de doctora en ciencias sociales, niñez y juventud, ofrecido por la Universidad de Manizales y el Centro Internacional de Educación, CINDE, única investigadora principal. La investigación se inscribió en el grupo de investigación Perspectivas políticas, éticas y morales de la niñez y la juventud, del Centro Internacional de Estudios Avanzados en Niñez y Juventud, CEANJ, escalafonado en la categoría A1 de Colciencias.

** Abogada, Universidad de Manizales. Magíster, CINDE. Especialista, Universidad de Manizales. Doctora en ciencias sociales, niñez y juventud. Profesora titular Universidad de Manizales.Contacto: mariateresa@mariateresacarreno.com, correo institucional: cis@umanizales.edu.co 


\section{RESUMEN}

Este artículo proviene de la investigación Concepciones de participación de los estudiantes de derecho en Colombia, realizada en diez programas de Derecho de cinco regiones diferentes del país. El enfoque metodológico es cualitativo y cuantitativo. Este artículo presenta la comprensión de la participación como utopía. En las conclusiones, propone una formación pluralista en derecho, resalta la tensión de la participación entre las constituciones de 1886 y 1991 y la necesidad de agudizar las prácticas en la formación de los estudiantes de derecho en Colombia. Finalmente, expone algunas hipótesis emergentes del estudio.

Palabras clave: participación; formación en derecho; democracia; ciudadanía 


\section{ABSTRACT}

This article is based on the research project Concepts of Participation of Law Students in Colombia, carried out in ten Law undergraduate programs in five different regions of the country. The methodological approach is qualitative and quantitative. This article shows the understanding of participation as an utopia. In the conclusions it proposes a pluralist Law education, highlights the tensions on participation between the constitution of 1886 and that of 1991, and also emphasizes the need to sharply improve the educational practices for law students in Colombia. Finally, it shows some emergent hypotheses of the study.

Keywords: participation; law education; democracy; citizenship

\section{SUMARIO}

Introducción.- I. Diseño metodológico.- II. Procedimientos, técniCas e instrumentos de ReColección de la información.- $A$. Fases.- $B$. Escenario de estudio.- C. Población y unidad de análisis.- D. Categorías y subcategorías de análisis.- III. ESTRATEGIAS DE RECOLECCIÓN DE INFORmación.- IV. Momento Descriptivo.- V. MOMEnto COMPRensivo.- VI. MOMENTO INTERPRETATIVO DE LAS CONCEPCIONES DE PARTICIPACIÓN DE LOS ESTUdiANTES DE DERECHO EN COLOMBIA.- VII. Resultados.- VIII. LA UTOPÍA DE LA PARTICIPACIÓN.- CONCLUSIONES.- BiBLIOGRAFía. 


\section{INTRODUCCIÓN}

La investigación que da vida a este artículo parte del supuesto de que la teoría en la que se forma a los estudiantes, las prácticas sociales, jurídicas y sus interacciones cotidianas definen su desempeño posterior dentro de la sociedad.

En esta investigación, una de las principales motivaciones es la Constitución Política (CP) de 1991, porque esta dio origen a un nuevo marco de relaciones sociales, económicas, políticas, culturales y ambientales; transformó la concepción del Estado en Colombia; y les otorgó un papel protagónico a los ciudadanos para que sean factor y motor de desarrollo. En suma, la Constitución promueve procesos de participación para hacer efectivo el ejercicio de la ciudadanía que les permita a los colombianos intervenir en los distintos ámbitos de acción de la sociedad.

Este nuevo impulso constitucional significa que los ciudadanos son reconocidos como sujetos de derechos, razón por la cual se legisla en esta materia y se adoptan prácticas institucionales que propician en la población una nueva forma de pensar, de actuar $\mathrm{y}$ de sentir. Tal afirmación no desconoce que anteriormente los ciudadanos se vinculaban de alguna manera a la construcción de los asuntos públicos; pero la configuración de la realidad social suscitada a partir de la nueva carta constitucional establece una nueva concepción del actor social, que exige transformar el pensamiento y la acción de las instituciones gubernamentales y no gubernamentales, públicas y privadas; de los gobernantes; de las organizaciones de la sociedad civil; de la familia; de la escuela y de la población en general. Estos postulados que emergen de la Constitución de 1991 han sido enriquecidos en este trabajo con los desarrollos normativos, jurisprudenciales, doctrinarios, teóricos y con los datos emergentes para comprender las concepciones de participación de los estudiantes de derecho.

En este contexto, el desarrollo de esta investigación se guía por la pregunta ¿cuáles son las concepciones de participación que tienen los estudiantes de derecho en Colombia? Se pretende resaltar en este trabajo la responsabilidad de los abogados, debido a su rol de operadores jurídicos que los obliga a desempeñarse en la esfera 
pública y privada con una especial apropiación de los postulados constitucionales.

El objetivo general de esta investigación fue comprender las concepciones de participación de los estudiantes de derecho en Colombia, mediante la comparación de las respuestas a las preguntas que se les formularon, con el propósito de aportar a la comprensión de este proceso y la posibilidad de mejorar la práctica formativa.

Por ello, es importante reconocer las ideas de los estudiantes de derecho del país en torno a la participación, lo que permite identificar los referentes teóricos inmersos en su formación y en su práctica de vida, y comprender cómo su quehacer como actores sociales y como ciudadanos contribuye a esa formación. Dada la responsabilidad social de la formación de los estudiantes de derecho como futuros profesionales que deben ejercer su profesión guiados por la Carta Constitucional, que valora tanto la participación, los resultados de este trabajo servirán de insumo para desentrañar la importancia de la formación de los estudiantes de derecho, sus contenidos y la tendencia en la teoría jurídica, dado que, a pesar del direccionamiento teórico constitucional, la práctica jurídica parece no reflejar los cambios sociales deseados.

Con la interpretación, el análisis de los datos y su comparación se comprendieron las diferencias y las semejanzas de las concepciones de participación de los estudiantes de diez programas de derecho, ubicados en Pasto, Florencia, Bucaramanga, Medellín, Bogotá y Manizales. Además, se comparó la teoría sustantiva emergente con la teoría formal, para construir nuevos marcos de sentido sobre las categorías de análisis propuestas y sobre las categorías emergentes.

\section{DISEÑO METODOLÓGICO}

La metodología con la que se abordó el estudio empírico en este trabajo es cualitativa y cuantitativa. La información cualitativa fue interpretada mediante un análisis de categorías emergentes y los datos cuantitativos fueron procesados mediante un análisis estadístico pues se buscó comprender las concepciones de participación de los estudiantes de derecho, y también se pudo comparar, cuantificar y relacionar estas concepciones. 
La comprensión de las concepciones de participación de los estudiantes de derecho en Colombia requiere el reconocimiento de la realidad humana como una construcción sociohistórica y cultural que media los procesos de aprendizaje del sujeto.

Dada la naturaleza del conocimiento que se busca construir, un estudio cualitativo ofrece una posibilidad teórica y metodológica apropiada para abordar el problema de investigación respecto a las concepciones de participación del estudiante de derecho puesto que el conocimiento de lo humano pasa necesariamente por los planos de lo subjetivo y lo intersubjetivo, pues el conocimiento mediado por procesos de aprendizaje no es un cuadro estático, sino que se moviliza en la dinámica de la búsqueda de sentido que implica la realidad humana.

Esto significa que la comprensión de los procesos humanos parte del reconocimiento de las interacciones, de otorgar contenido y significado a la acción como método válido de estudio en las ciencias sociales. Al respecto, Johann Gustav Droysen plantea que el ser humano expresa su interioridad mediante manifestaciones sensibles y el no captar la parte interna de un hecho, acción social o conducta equivale a no comprenderlo ${ }^{1}$. Desde entonces, la comprensión representa una concepción metodológica propia de las ciencias sociales.

En ese sentido, en este trabajo se procura comprender las concepciones que han construido los estudiantes de derecho en Colombia, mediante el aprendizaje obtenido por las experiencias de la vida cotidiana y la educación institucionalizada en los programas de derecho influidos por la Constitución Política.

Esta elección tiene un carácter hermenéutico, porque se busca descifrar los textos producidos por los estudiantes y encontrar el sentido que adquieren en su contexto. La interpretación es una construcción cultural que trasciende la sola explicación de los hechos o fenómenos para llegar a comprender lo que se estudia. Por eso, el proceso interpretativo está asociado al sentido, porque siempre que se interpreta un texto se pregunta por qué está escrito

1 Johann Gustav Droysen, Grundriss der historik, en Die Erklären: Verstehen Kontroverse in Transzendental Pragmatischer Sicht (Karl OtTo Apel, Frankfurt, Suhrkamp, 1858), citado por José María Mardones, Filosofía de las ciencias humanas y sociales. Materiales para una fundamentación científica, 30 (Anthropos, Barcelona, 1991). 
y qué sentido tiene. Ahora bien, respecto al método, la elección de alguno se concibe como una ayuda para la comprensión, pero no como su procedimiento necesario. Y esto se asevera, porque, según Darío Alberto Ángel-Pérez y José Darío Herrera:

En ciencias sociales no se afirma la existencia de un método, como si hubiera uno único, para enfrentar cualquier fenómeno humano, histórico, social y para cualquier disciplina. Se afirma, más bien, la pluralidad de métodos que convergen en torno al diálogo como posibilidad de aproximación a lo humano².

Con esta advertencia referida a la crítica de la hermenéutica, al método como criterio de validez científica y como apertura de los métodos científicos, es posible comprender que la interpretación sobre el sentido de los textos obtenidos es un permanente ir y regresar a ellos según el contexto en el que van apareciendo. En esta investigación, la pregunta por el sentido se refiere a la búsqueda de las concepciones de participación de los estudiantes de derecho en Colombia. La comprensión de esas concepciones tiene una finalidad en el tiempo, referida a la Constitución Política, y a las necesidades de la sociedad que exige la operacionalización de una Constitución que no puede quedarse en el mero discurso y que requiere una mayor coherencia entre la academia y la acción, el discurso y la práctica y se trata de comprender este sentido respecto a esa finalidad de la participación en el país.

El estudio se planteó en tres escenarios en los que se dio cuenta de las concepciones de participación. El primero se refiere a la teoría en que, a partir de la doctrina, la ley (la Constitución) y la jurisprudencia, se indagó sobre las nociones de participación y sus categorías centrales. El segundo escenario son los currículos de las facultades de derecho; y el tercero, el contexto político, formativo y cultural de los estudiantes de derecho.

Posteriormente, se plantearon las categorías iniciales en los dos primeros escenarios que fueron los ítems del instrumento con el cual se recogió la información del tercer escenario. Con base en esta información, se realizó un análisis estadístico de las encuestas.

2 Darío Alberto Ángel-Pérez \& José Darío Herrera, La propuesta hermenéutica como crítica y como criterio del problema del método, 43 Estudios de Filosofía, 9-29, 11 (2011). Disponible en: http://aprendeenlinea.udea.edu.co/revistas/index.php/estudios_de_filosofia/article/viewFile/11565/10543 
Se procedió a realizar un análisis de contenido, cuyos procedimientos tuvieron el propósito de plantear preguntas y producir un metatexto. Se seleccionó esta técnica porque las estrategias y los procedimientos de análisis tienen como fundamento el lenguaje en sus dimensiones simbólica e intersubjetiva, y en su naturaleza social, fundamentos compatibles con los presupuestos teóricos del presente estudio. A partir de esta interpretación, se reconocieron las categorías emergentes implícitas en la información. Luego, se cruzaron esas categorías y se analizaron, para producir un primer resultado que pudiera ser contrastado con los datos emergentes de la encuesta, a la cual se le hizo un análisis cualitativo en el que se definieron y determinaron categorías.

El abordaje cuantitativo se realizó sobre la información de las encuestas, mediante el análisis multivariado de casos. Con este análisis, se buscó conocer y documentar la experiencia de los estudiantes que se forman en las facultades de derecho para identificar sus concepciones sobre los procesos participativos, los logros, las dificultades, los avances y los retos surgidos de las exigencias de formación profesional de la educación superior.

El análisis multivariado de categorías se relaciona con las tablas de contingencia, que son los resúmenes estadísticos más utilizados en ciencias sociales. Las observaciones efectuadas por la encuesta de segmentos de realidad social son, a menudo, resumidas en una serie de tablas de contingencia y la investigadora se enfrenta a la necesidad de interpretar las relaciones que se manifiestan en lo observado, a partir de los resúmenes estadísticos.

Se realizó a continuación una lectura multivariada sobre las diversas categorías o modalidades de variables que expresan la participación de los estudiantes de derecho de diez universidades del país, en los semestres octavo, noveno y décimo. En esta lectura, se identificaron diversos grupos de acuerdo con las respuestas obtenidas de los estudiantes, construidas por la cercanía entre ellos, es decir, por la selección global de las modalidades. La proximidad entre modalidades de variables diferentes respecto a la asociación, corresponde a puntos medios de estudiantes que las han seleccionado y son próximas porque están ligadas a estos individuos o a otros semejantes. 
El análisis de correspondencias múltiples encuentra asociaciones entre variables categoriales por medio de sus respectivas modalidades y sobre estas asociaciones se elabora una descripción comprehensiva y compleja de la participación como fenómeno político. La inferencia descansó sobre el análisis multivariado y también sobre el análisis cualitativo.

\section{PROCEDIMIENTOS, TÉCnicas E INSTRUMENTOS DE RECOLECCIÓN DE LA INFORMACIÓN}

Para dar respuesta a la pregunta que guía la investigación, se obtuvo la información en tres fases simultáneas teniendo en cuenta los tres escenarios planteados. El análisis conceptual de la Constitución y de los currículos de las facultades elegidas, la encuesta y el grupo focal fueron las estrategias que se utilizaron para obtener la información necesaria.

\section{A. Fases}

1. Para la primera se realizó un análisis del contenido de la Constitución Política en lo referente a la participación. En esta fase, se identificaron algunas categorías jurídicas en la $\mathrm{CP}$ que caracterizan la participación.

2. Para el segundo escenario se realizó un análisis del contenido de los currículos de los diez programas elegidos. Se identificaron las categorías encontradas sobre la participación y relación con la CP. Con el fin de realizar una triangulación y obtener una mejor comprensión del segundo escenario, se realizó un grupo focal con docentes de los programas elegidos en esta investigación sobre el objeto de estudio y los procesos de formación de los estudiantes de derecho.

Las categorías y variables derivadas de las dos fases anteriores fueron el insumo para la elaboración de la encuesta a 287 estudiantes sobre la participación, sus categorías y relación con el currículo. La encuesta se realizó desde la prosopografía, según Juan Manuel Castellanos-Obregón: 
La prosopografía es la interpretación de las relaciones internas de un colectivo. Tiende a realizarse en investigaciones retrospectivas mediante el análisis de conjuntos de variables uniformes... ${ }^{3}$ Esta metodología desarrollada con alguna predilección por los historiadores franceses vendría de su voluntad de privilegiar los hombres en sus investigaciones, contrariamente a los investigadores anglosajones, más interesados en las cifras... ${ }^{4}$.

Las encuestas fueron iguales para todos y exploraron sus ideas de participación no institucionalizada sino desde la perspectiva de Thomas Luckmann ${ }^{5}$, quien explora el origen de la sociedad por medio de la acción; también se indagó en la encuesta sobre los ideales que sustentan la participación en la Constitución de 1991 como derecho fundamental, principio, fin, deber, con el objetivo de triangular el postulado axiológico con las vivencias de los estudiantes; el fundamento teórico lo proporcionaron Luis Tapia, Norberto Bobbio, Boaventura de Sousa Santos y Amartya Sen ${ }^{6}$, entre otros; estas categorías aluden al Estado social de Derecho y se fundamentan en los derechos de igualdad y libertad, y en el ejercicio de ellos se hace posible la participación. Otro grupo de preguntas versó sobre los procesos de formación y la inclusión de las prácticas de acuerdo con lo planteado en la problematización, se abordó desde la relación entre la formación teórica y práctica ${ }^{7}$ Y

3 Juan Manuel Castellanos-Obregón, Formas actuales de la movilización armada: una aproximación prosopográfica, 75, Tesis de doctorado en ciencias sociales, niñez y juventud, Centro de Estudios Avanzados en Niñez y Juventud, CEANJ, Universidad de Manizales, Centro Internacional de Educación, CINDE (2009). Disponible en: http://biblioteca.clacso.edu.ar/ Colombia/alianza-cinde-umz/20130225065635/juanmanuelcast.pdf

4 Alain Plessis, Histoire bancaire et prosopographie, 9 Bulletin des liaison des sociétés savantes, 3-4, 3 (mars 2004). Disponible en: http://cths.fr/_files/an/pdf/bulletin9.pdf, citado por JUAN Manuel Castellanos-Obregón, Formas actuales de la movilización armada: una aproximación prosopográfica, 76, Tesis de doctorado en ciencias sociales, niñez y juventud, Centro de Estudios Avanzados en Niñez y Juventud, CEANJ, Universidad de Manizales, Centro Internacional de Educación, CINDE (2009). Disponible en: http://biblioteca.clacso.edu.ar/ Colombia/alianza-cinde-umz/20130225065635/juanmanuelcast.pdf

5 Thomas Luckmann, Teoría de la acción social (Paidós Ibérica, Barcelona, 1996).

6 Luis Tapia-Mealla, La velocidad del pluralismo. Ensayo sobre tiempo y democracia (Muela del Diablo Editores, La Paz, 2002). Norberto Bobbio, Liberalismo y democracia (México D.F., Fondo de Cultura Económica, colección Breviarios FCE, 1989). Norberto BobBio, Igualdady Libertad (Paidós y el Instituto de Ciencias de la Educación, ICE, de la Universidad Autonóma de Barcelona, UAB, Barcelona, 1993). Boaventura de Sousa Santos, El milenio huérfano, ensayos para una nueva politica (Trotta, Bogotá, 2005). AmARTYA K. SEN, Desarrollo y libertad (Planeta, Barcelona, 2000).

7 Así lo manifiestan varios autores: Víctor E. AвrAmovich, La enseñanza del derecho en las clínicas legales de interés público: materiales para una agenda temática, en Defensa Jurídica del Interés Público, Enseñanza, estrategias, experiencias, 61-94 (Universidad Diego Portales, Santiago de Chile, 1999). Disponible en: http://www.udp.cl/descargas/facultades_carreras/ 
por último, la participación en movimientos sociales, fundamentada teóricamente en la construcción social del conocimiento ${ }^{8}$.

Una vez obtenidas las categorías con las fases anteriores, se realizó un análisis mixto en el que el análisis cualitativo y el análisis estadístico se cruzaron en un análisis multivariado para establecer factores de concepción de la participación entre el sistema normativo, programas de derecho y prácticas, ideales, sueños, concepciones e ideas de los estudiantes de derecho. En esta fase, se aplicó el análisis multicategorial.

3. Una parte fundamental del currículo son los profesores, por lo cual se realizaron paralelamente grupos focales con docentes de los programas de derecho implicados en este proceso investigativo. Con ellos, se realizaron seis grupos focales en Pasto, el Eje Cafetero, la Amazonía, Santander, Medellín y Bogotá, con las siguientes preguntas:

a. ¿Cuál es el objeto de estudio del Derecho de acuerdo con la macroestructura curricular de su programa?

b. ¿Cuál es el enfoque metodológico?

c. ¿Qué estrategias metodológicas proponen en el aula?

En esta discusión, importaba triangular la propuesta curricular vigente en los programas de derecho en Colombia, para comprender el espectro de la participación en la formación.

\section{B. Escenario de estudio}

La investigación se llevó a cabo en diez facultades de derecho, cinco públicas y cinco privadas, de seis ciudades del país (Pasto, Floren-

derecho/pdf/investigaciones/Cuadernos_de_analisis_Coleccion_Derecho_Privado/especiales/CAJ_n09_Serie_Publicaciones_Especiales.pdf, http://www.palermo.edu/derecho/pdf/ Bibliografia-clinicas-juridicas/la_ensenanza_del_derecho_en_las_clinicas_legales_de_interes_publico $\% 282 \% 29$.pdf. Anthony G. Amsterdam, Clinical Legal Education, A $21^{\text {st }}$ Century Perspective, 34 Journal of Legal Education, 4, 612-618 (1984). MARTIN BöHMER, Introducción, en La enseñanza del derecho y el ejercicio de la abogacía, 13-23 (MARTin BöHMER, comp., Gedisa, Barcelona, 1999). Alba Esther de Bianchetti, Susana Alejandra Fridman \& Hilda Zulema ZÁRATE, La evaluación del proceso enseñanza-aprendizaje del derecho (Resumen S-008, en línea, Universidad Nacional del Nordeste, Corrientes, 2003). Disponible en: http://www.unne.edu. ar/unnevieja/Web/cyt/cyt/2003/comunicaciones/01-Sociales/S-008.pdf

8 Boaventura de Sousa Santos, El milenio huérfano, ensayos para una nueva política (Trotta, Bogotá, 2005). Mauricio García-Villegas, dir., Normas de papel, la cultura del incumplimiento de reglas de justicia (Siglo del Hombre Editores, Bogotá, 2009). Hugo Zemelman, Pensamiento crítico y neoliberalismo en América Latina (Universidad Pedagógica Nacional, Bogotá, 2010). 
cia, Bucaramanga, Medellín, Bogotá y Manizales). Se escogieron según la ubicación geográfica, con lo que se dio un cubrimiento importante que representa las regiones sur, norte, occidente, oriente y centro, en las que se ubican facultades de universidades públicas y privadas.

La selección de las mencionadas ciudades también se debió al interés de la investigadora por comparar los datos en las instituciones y en su relación con otras, con el propósito de leer la forma en que influyen los contextos en las concepciones de los estudiantes y en sus procesos de formación. El perfil de las facultades requería tener como mínimo su registro calificado lo que les da un estándar de igualdad que permite concluir que tienen las mismas condiciones de funcionamiento.

\section{Población y unidad de análisis}

En cada institución se encuestó la totalidad de los estudiantes que se encontraban cursando los dos últimos semestres de la carrera. El total de estudiantes encuestados fue de 287.

Las concepciones de participación en los escenarios propuestos - es decir, la teoría, los currículos y la práctica social en la que interactúan los estudiantes de derecho - constituyen la unidad de análisis.

\section{Categorias y subcategorias de análisis}

La categoría de análisis elegida fue la participación y para proceder a su interpretación y comprensión se eligieron los siguientes escenarios: concepciones de participación de los estudiantes de derecho, los currículos de las facultades de derecho, el escenario social y el ambiente cultural.

\section{ESTRATEGIAS DE RECOLECCIÓN DE INFORMACIÓN}

Para la recolección de datos se utilizaron varias fuentes de información; entre estas, tenemos: compilación de normas constitucionales sobre la participación, recopilación de los currículos de las facul- 
tades de derecho elegidas, encuesta y grupo focal, la utilización de estas fuentes de información permitió que la investigadora dotara de nuevas interpretaciones los asuntos relacionados con la participación, sin pretender con este análisis plantear generalizaciones. En segundo lugar, se hizo un análisis cruzado de los resultados obtenidos en las fuentes de información empleadas. Las fuentes de información se organizaron mediante una matriz de recolección de información que indicaba la temporalidad en la recolección y los objetivos de los instrumentos.

Al respecto, tenemos:

\section{Tabla 1. Estrategias de recolección de información}

\begin{tabular}{|c|c|c|}
\hline $\begin{array}{l}\text { Estrategia de } \\
\text { recolección de la } \\
\text { información }\end{array}$ & Temporalidad & Objetivo \\
\hline $\begin{array}{l}\text { Revisión de la normati- } \\
\text { va constitucional }\end{array}$ & $\begin{array}{l}\text { Se revisaron la norma- } \\
\text { tiva, la doctrina y la } \\
\text { jurisprudencia constitu- } \\
\text { cional. }\end{array}$ & $\begin{array}{l}\text { Reconocer la propuesta } \\
\text { constitucional de la par- } \\
\text { ticipación en Colombia. }\end{array}$ \\
\hline $\begin{array}{l}\text { Revisión de los currícu- } \\
\text { los de los programas de } \\
\text { derecho elegidos }\end{array}$ & $\begin{array}{l}\text { Se revisaron los elemen- } \\
\text { tos principales consti- } \\
\text { tutivos del currículo: } \\
\text { misión, visión, objeti- } \\
\text { vos, planes de estudio, } \\
\text { modelo pedagógico, } \\
\text { concepción de los do- } \\
\text { centes sobre la forma- } \\
\text { ción de los estudiantes. }\end{array}$ & $\begin{array}{l}\text { Precisar las categorías } \\
\text { teóricas emergentes } \\
\text { de la formación de los } \\
\text { estudiantes de derecho } \\
\text { que definen y le dan } \\
\text { significado a la partici- } \\
\text { pación. }\end{array}$ \\
\hline $\begin{array}{l}\text { Aplicación de la en- } \\
\text { cuesta a } 287 \text { estudiantes } \\
\text { pertenecientes a los } \\
\text { programas incluidos en } \\
\text { esta investigación }\end{array}$ & $\begin{array}{l}\text { Se elaboró el instrumen- } \\
\text { to, a partir de las cate- } \\
\text { gorías emergentes de los } \\
\text { otros escenarios y de los } \\
\text { objetivos pendientes en } \\
\text { la investigación. }\end{array}$ & $\begin{array}{l}\text { Reconocer las concep- } \\
\text { ciones de participación } \\
\text { de los estudiantes de } \\
\text { derecho, según sus ideas } \\
\text { personales, sus prácti- } \\
\text { cas, sus desempeños y } \\
\text { sus aprendizajes. }\end{array}$ \\
\hline Realización grupo focal & $\begin{array}{l}\text { Se elaboraron las } \\
\text { preguntas teniendo en } \\
\text { cuenta las categorías } \\
\text { emergentes, objetivos de } \\
\text { la investigación. }\end{array}$ & $\begin{array}{l}\text { Triangular la infor- } \\
\text { mación concerniente } \\
\text { a la formación de los } \\
\text { estudiantes, según sus } \\
\text { docentes. }\end{array}$ \\
\hline
\end{tabular}

Fuente: elaboración propia 
Antes de iniciar la recolección de información, se estructuraron los instrumentos y se sometieron a juicio de expertos.

\section{MOMENTO DESCRIPTIVO}

En este momento, la investigadora trabajó en dos niveles de análisis:

\section{Tabla 2. Niveles de análisis}

\begin{tabular}{|c|c|c|}
\hline Textos & Niveles de análisis & Contexto \\
\hline $\begin{array}{c}\text { Normas, jurisprudencia y doctri- } \\
\text { na de la Constitución Política }\end{array}$ & Momento descriptivo & Teórico \\
\hline Currículos & Momento descriptivo & $\begin{array}{c}\text { Teórico } \\
\text { Grupo focal }\end{array}$ \\
\hline Encuestas, grupos focales & Momento descriptivo & $\begin{array}{c}\text { Condiciones } \\
\text { Prácticas }\end{array}$ \\
\hline
\end{tabular}

Fuente: elaboración propia

\section{MOMENTO COMPRENSIVO}

Este momento consistió en la organización y sistematización de toda la información, para relacionarla con las preguntas y objetivos de investigación.

\section{MOMENTO INTERPRETATIVO DE LAS CONCEPCIONES DE PARTICIPACIÓN DE LOS ESTUDIANTES DE DERECHO EN COLOMBIA}

Este momento consistió en la producción escrita del metatexto que relaciona el texto y el contexto con los presupuestos teóricos desarrollados en este estudio y con otros postulados requeridos para interpretar las concepciones sobre la participación, resultado de las evidencias empíricas. En este momento, se elaboraron las categorías interpretativas que permitieron acceder a una nueva forma de comprensión y análisis de las concepciones de participación de los estudiantes de derecho y de la realidad en la que se despliega 
este corpus. Mientras en los momentos descriptivo y comprensivo, las encuestas, el grupo focal, la CP y los currículos fueron el lugar central de análisis, en este último momento interpretativo la investigadora jugó un papel central, pues en ella recayó la responsabilidad de dotar de un nuevo sentido analítico a:

- Las concepciones proferidas por los estudiantes.

- Las evidencias empíricas del contexto.

- La pregunta de investigación y los objetivos.

- Los presupuestos teóricos orientadores del estudio.

\section{RESULTADOS}

Los resultados se sustentan en la interpretación de la información y se apoyan en el análisis comparado de las categorías que, de acuerdo con la interpretación, constituyen las concepciones de participación de los estudiantes de derecho; las categorías emergieron del análisis cualitativo de los datos.

En un primer panorama, se organizaron con cercanías y distancias las variables y las categorías. A partir de allí, se proyectaron las concepciones de participación de los estudiantes de derecho, así: la participación como utopía, la participación del derecho fundamental a metaderecho, la participación legal, la subjetividad de los estudiantes de derecho en Colombia. Estas concepciones se sustentan en las categorías de acción, reflexividad y democracia, fin, principio, currículo activo y reflexivo, político, integral, mediante las cuales se compararon las variables mecanismos de protesta, mecanismos de participación, aprendizaje (humanísticas) y prácticas (sociales), derecho fundamental y metaderecho, las categorías afines de currículo - político, integral-, el uso de mecanismos de participación, aprendizaje, derecho público y prácticas (jurídicas), deber, prácticas (jurídicas, mecanismos), aprendizaje derecho público y los mecanismos de participación individuales. 


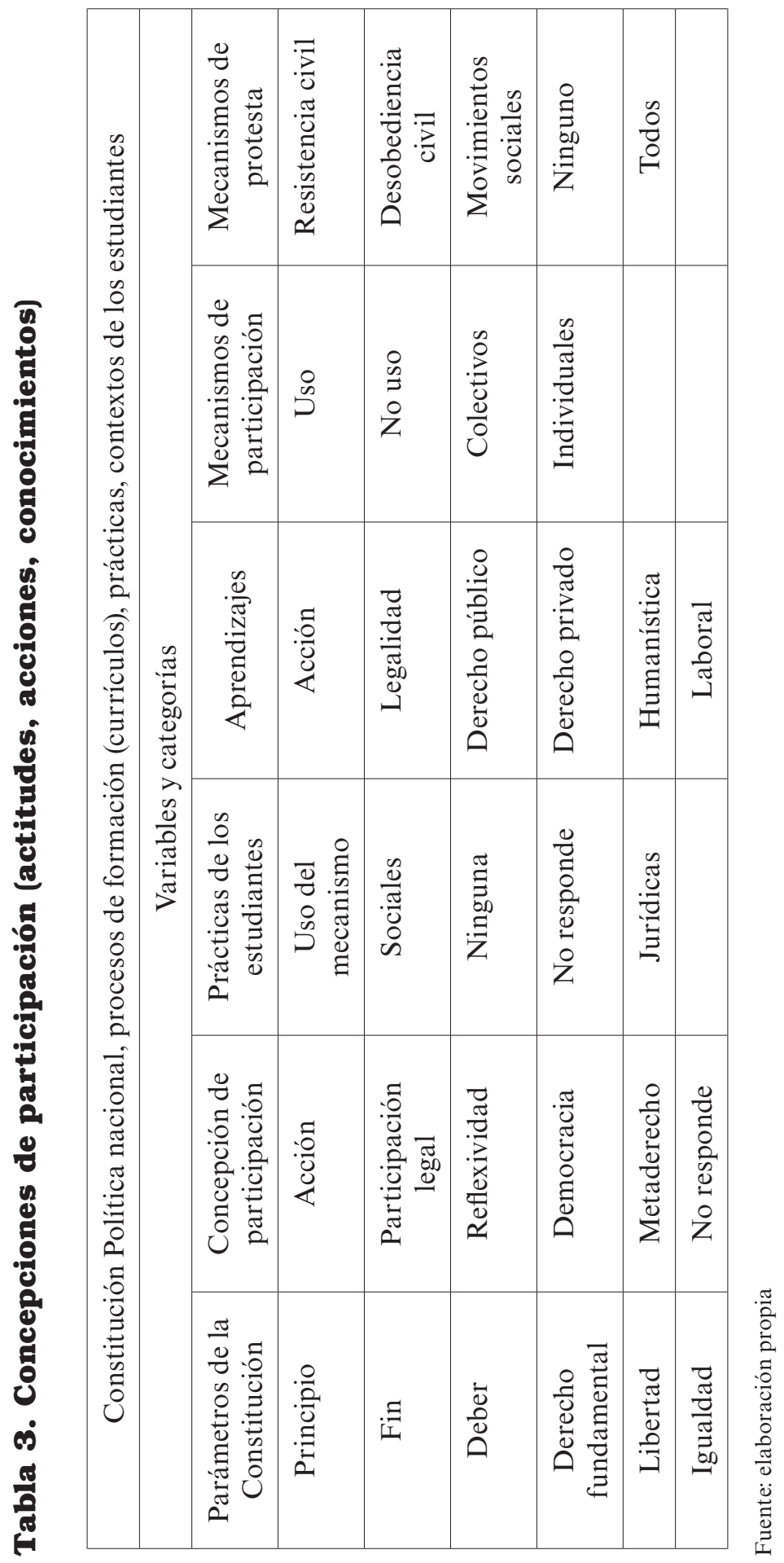


Las categorías se agruparon por afinidad entre ellas, para constituir tipos ideales de la participación, como el que se presenta en este artículo:

\section{LA UTOPÍA DE LA PARTICIPACIÓN}

Los estudiantes aluden a formas de acción cuando piensan en la participación: "considero que es el derecho de la ciudadanía para hacer parte activa de las decisiones que se tomen en torno a su funcionamiento como sociedad". Para otros, es la "facultad que tenemos los ciudadanos para participar y aportar en las decisiones y direcciones del Estado".

La categoría acción es reiterativa y se dirige a reconocer un actuar del ciudadano frente a las necesidades, decisiones, consultas y demás situaciones políticas del país: "Es el derecho que tenemos todos de poder involucrarnos y participar activamente en las decisiones que se toman para el bien de todos". Esta categoría emergente está referida a la acción política: "Es un derecho de todo ciudadano en un gobierno democrático que consiste en involucrarse activamente en las decisiones gubernamentales". Es preciso analizar esta perspectiva en la dimensión de lo político.

Al respecto, Hannah Arendt tiene una concepción de la acción como un comienzo, o nacimiento y este último lo compara con la natalidad, en el sentido de que es una nueva puesta en escena, un descubrir el mundo al cual se llega ${ }^{9}$. Arendt presenta la acción como el fenómeno por el cual los sujetos pueden transformar su mundo político, pero para ello se requiere un espacio común, de un algo que sea de todos, tal como lo plantean los estudiantes encuestados, refiriéndose a la participación: "Medio idóneo que tienen las personas o ciudadanos, para actuar frente a las políticas del Estado". $\mathrm{O}$ "es el ejercicio mediante el cual las personas que hacen parte de una sociedad manifiestan sus necesidades y soluciones a estas". Otros sostienen que son "las personas que utilizan los espacios políticos de discusión propios para tomar decisiones que competen a la sociedad".

9 Hannah Arendt, La condición humana, 215, 218 (Paidós, Barcelona, 1993). 
Según Hannah Arendt ${ }^{10}$, la acción es la actividad mediante la cual los seres humanos pueden transformar el mundo de la vida política. Para ello, se requiere la participación de la comunidad en un espacio público en el que, según los estudiantes entrevistados, los ciudadanos puedan obrar, expresar y deliberar libremente, "es la posibilidad que tienen los ciudadanos de intervenir en las diferentes áreas, esferas de la vida en comunidad, en especial, en la toma de decisiones que afectan sus destinos, como elección de sus representantes, aprobación de decisiones importantes por referendo, plebiscito, etc. Y realizar un control, por ejemplo, veedurías".

En este sentido, la acción es la "actividad política por excelencia" "11 y este es el mismo planteamiento de los estudiantes de Derecho: "es la posibilidad que tienen los ciudadanos de ser activos en el proceso político del país, en donde estos, por medio de los diferentes mecanismos, contribuyen al desarrollo del mismo". "Posibilidad que tenemos todos de decir lo que se piensa, de traducir esto en acciones que influencien el manejo de lo público".

De allí que esta acción planteada por los estudiantes y triangulada con la postura de Arendt requiere la existencia de un espacio común: "es la posibilidad de participar activamente como asociados de un Estado" (encuesta a estudiante). Este espacio es el Estado donde los "asociados" tienen un derecho que pueden reclamar, que pueden construir y un deber que deben aportar. Las afirmaciones de los encuestados hacen alusión a la necesidad de una comunicación con los otros para que esta acción sea posible: "la posibilidad de decir lo que uno piensa" es necesaria que haya una interlocución que se construye direccionada por una organización política y social que le da vida. Esta postura es constante en las respuestas de los estudiantes respecto al Estado social de derecho, a la democracia participativa y a los elementos jurídicos, axiológicos, sociales y económicos contenidos en la Constitución Política. Estas posiciones son expresadas de la siguiente manera: "es la participación proactiva de todos los ciudadanos en pro de la convivencia y buen desarrollo social, la posibilidad que tienen todos los colombianos de ejercer un papel activo en el sistema democrático del país" (encuesta a estudiante). "Capacidad y derecho de toda persona para

10 Hannah Arendt, La condición humana, 28 (Paidós, Barcelona, 1993).

11 Hannah Arendt, La condición humana, 23 (Paidós, Barcelona, 1993). 
participar en la democracia y Estado social de derecho". Estos testimonios indican que no se trata de una acción suelta sino ligada referencialmente en sus conceptos a la organización del Estado como Estado social de derecho.

En este sentido, para que la acción se produzca, es necesaria la interacción con otros, es necesaria el habla construida por el nosotros, que permite reconocer un espacio común: "gracias a la acción y la palabra es que el mundo se revela como un espacio habitable, un espacio en el que es posible la vida en sentido no biológico (bios) ${ }^{12}$, los estudiantes reconocen ese espacio en el discurso de la Constitución, cuando hacen referencia al acervo de derechos y deberes, al Estado social de derecho, a los principios comunes, y en el mismo Estado como espacio que nos pertenece: "es participar activamente en cada una de las consultas que se realicen en nuestro país" (entrevista con estudiante). La acción es posible en el reconocimiento de ese contexto común: "en tanto que agentes, somos al mismo tiempo sujetos perceptores y objetos percibidos, formamos parte de un contexto"13.

A ese contexto hacen referencia los estudiantes, convencidos de que la acción no puede darse en solitario y de que es necesaria una comunidad de intereses que los oriente. Es frecuente encontrar en las respuestas de los estudiantes la categoría de lo común, de lo de todos, de lo público como un bien que se debe salvaguardar: "es contribuir a regular el orden público de la sociedad, teniendo en cuenta las normas constitucionales", "contribuir a la sociedad en cualquier situación", "una forma de participar democráticamente en decisiones políticas de interés general", "es la posibilidad que tenemos de interactuar en la vida pública de nuestro país, proponiendo, eligiendo" (entrevista con estudiante). Y esta es una referencia a la Carta constitucional que contiene los principios rectores de la convivencia social.

La acción que surge de los datos aportados por los estudiantes es una acción política en términos de Arendt, para quien la acción política no es posible sin el discurso mediador que construye y da significado a las prácticas sociales, y en las que también se hace imprescindible el contexto caracterizado por los estudiantes como

12 Hannah Arendt, La condición humana, 18 (Paidós, Barcelona, 1993).

13 Hannah Arendt, La condición humana, 18 (Paidós, Barcelona, 1993). 
el Estado social de derecho y las múltiples posibilidades de dar vida a los derechos y deberes de un grupo social. De esta manera, la pluralidad es también indispensable para la acción, solo es posible actuar donde hay un conglomerado, donde hay otros; en la pluralidad se evidencia el sujeto individualizado que participa con sus intereses y es activo, aunque se ve afectado con las acciones de los otros. Esta acción política está caracterizada por la libertad del sujeto. Para poder actuar, lo hace porque está orientado por intereses individuales o colectivos pero no necesariamente la acción impacta obligatoriamente a la comunidad, eso puede suceder o no.

En esta construcción del espacio por medio de la acción, cabe el concepto de poder de Arendt: "poder y violencia son excluyentes. El poder se genera en un tejido de relaciones interpersonales, en un 'entre' (inbetween) fundado en la acción y en los discursos"14. Los espacios conceptualizados por los estudiantes como contextos en los que es posible una acción direccionada al bien común bien puede constituirse en un espacio de poder colectivo, y la condición para que este poder tenga lugar es el encuentro intersubjetivo mediante el diálogo que permite la concertación sobre las necesidades de la comunidad: "la participación es la forma en que la población accede e interviene en las decisiones gubernamentales que la afectan, siendo una tarea del Estado garantizar los mecanismos para que los ciudadanos mediante sus opiniones propias puedan hacer parte de un proceso democrático y formar y ayudar a desarrollar el mismo gobierno en que habitan", "es la facultad que tienen los ciudadanos de intervenir activamente en las decisiones del Estado". "Es la participación activa de cada persona en los asuntos políticos en defensa de los deberes y derechos de todos y cada uno". El espacio público y la vida política de la comunidad se sostienen mediante este apoyo basado en la convicción ${ }^{15}$.

Ese espacio abierto en que es posible la acción no necesariamente coincide con el espacio físico. En términos de Arendt, es lo que les permitió a los griegos sostener que la polis es una "forma de organización" que puede desplazarse: "a cualquier parte que vayas, serás una polis"16, es también el espacio teórico o ideológico donde

14 Hannah Arendt, La condición humana, 222 (Paidós, Barcelona, 1993).

15 Hannah Arendt, La condición humana, 223 (Paidós, Barcelona, 1993).

16 Hannah Arendt, La condición humana, 221 (Paidós, Barcelona, 1993). 
una acción puede desarrollarse; en lo planteado por los estudiantes encuestados, el espacio fundamentalmente está dado por el Estado social de derecho.

Este espacio puede ser todavía débil en nuestro contexto, pero ello no le quita validez a la acción. En este sentido, Julio César Vargas-Bejarano plantea:

Sin embargo, el espacio de aparición es frágil, pues puede sucumbir ante la actitud de indiferencia y al desgano de los ciudadanos. En efecto, si todos los miembros de la comunidad se llegaran a comportar así, esta entraría en crisis e incluso desaparecería. Si la acción se rige por el principio de la utilidad, de la estrategia (tal y como sucede en la violencia y en la guerra), entonces, se destruye el tejido de las relaciones interpersonales; los discursos quedan al nivel de habladurías o de ideologías que se utilizan para ilusionar o engañar al otro, pero no revelan las intenciones auténticas, ni presentan a quien habla. La acción política pierde así su especificidad o sentido propio y se vuelve violenta. La consolidación de una cultura, o su desaparición dependen de la fortaleza del 'espacio de aparición' y del poder que en él se realiza mediante una coherencia entre los discursos y la acción. Debido a su carácter potencial, el poder necesita de algo que le otorgue sustento y permanencia: la autoridad o la institucionalidad jurídica ${ }^{17}$.

Es el caso de la acción política planteada por los estudiantes, es una acción válida expresada en sus respuestas y que alcanza connotaciones en el espacio público. Para ellos, este es el Estado social de derecho, que no necesariamente resulta coincidente con el Estado real.

De las expresiones así consideradas, 36 tenían alguna anotación entre paréntesis con acotaciones como esto no se cumple, esto es una promesa, esto es una utopía.

En los currículos de los programas de derecho, uno de los objetivos reiterativos es la reflexión: "formar sujetos reflexivos", "educar para la reflexión", "el centro de la formación es un sujeto autónomo y reflexivo". Estas son algunas de las premisas contenidas en las misiones, objetivos, propósitos, perfiles o valores de los programas. No obstante, las concepciones de los estudiantes de derecho expresan un pensamiento reflexivo: "Es la posibilidad que tiene cualquier

17 Julio César Vargas-Bejarano, El concepto de acción política en el pensamiento de Hannah Arendt, 11 Eidos, Revista de Filosofía de la Universidad del Norte, 82-107, 101 (2009). Disponible en: http://www.redalyc.org/articulo.oa?id=85412265004 
persona de ser parte de las decisiones tomadas en la ciudad o en el contexto que se encuentre para que pueda de igual manera oponerse a aquellas decisiones que lo perjudiquen socialmente" (entrevista con estudiante). En términos de Carlos Thiebaut:

El entrelazamiento práctico de las dos lógicas (autonomía, autenticidad), y nuestra capacidad de pasar de una a la otra al considerar los diferentes rasgos relevantes de una acción o un comportamiento, rasgos que están, como lo dijimos, contextualizados e institucionalizados, parece requerir de la subjetividad moral un cierto poder (y siento que esta puede ser una peligrosa metáfora). Cabe llamar a ese poder reflexividad. Este poder denotaría, en primer lugar, la capacidad de tomar distancia crítica frente a diversos contextos, permitiéndonos no estar atados a un conjunto prefijado de expectativas y de atribuciones en la interacción ${ }^{18}$.

Para alcanzar un sujeto reflexivo, se requiere que sea autónomo. En este sentido, Jürgen Habermas plantea:

Las personas legales privadas no pueden ni siquiera alcanzar libertades individuales privadas a no ser que ellas mismas alcancen, en un ejercicio conjunto de su autonomía como ciudadano, una conciencia clara de los intereses y criterios legítimos implicados en el caso y lleguen a un acuerdo sobre aquellos aspectos y criterios según los cuales cosas iguales han de ser tratadas igualmente y cosas diferentes de manera diferente. [...] Y si tomamos en serio esta relación interna entre el imperio de la ley y la democracia, se hace inmediatamente claro que el sistema de derechos no solo no es ciego a la desigualdad de las condiciones sociales de vida, sino que tampoco lo es en absoluto a las diferencias culturales ${ }^{19}$.

Esto implica que el individuo autónomo es tal en la medida en que pueda decidir y actuar en libertad, con capacidad de reconocer lo que puede ser bueno tanto para él como para la sociedad. Al respecto, Will Kymlicka sostiene que:

La voz autonomía significa cosas diferentes para personas diferentes. Utilizo el término para referirme a la capacidad de reflexionar racionalmente sobre nuestros conceptos de vida buena, así como a la de tener la facultad potencial de revisarlos. Una persona autónoma es capaz de reflexionar sobre sus fines vigentes y de valorar si esos fines siguen mereciendo su lealtad. Desde este punto de vista, la autonomía es congruente con el hecho de que las personas

18 Carlos Thiebaut, Vindicación del ciudadano, un sujeto reflexivo en una sociedad compleja, 116 (Paidós, Barcelona, 1998).

19 Jürgen Habermas (1994), citado por Carlos Thiebaut, Vindicación del ciudadano, un sujeto reflexivo en una sociedad compleja, 134 (Paidós, Barcelona, 1998). 
respalden el estilo de vida que han heredado si reflexivamente lo prefieren a las alternativas ${ }^{20}$.

Tal como se planteó en la categoría acción, la autonomía individual se construye en espacios colectivos, por lo cual la autonomía debe alcanzar la conciencia de intereses; con la configuración de la autonomía individual, es posible alcanzarla colectivamente, pues la formación de un sujeto reflexivo exige la formación inicial de un sujeto autónomo, libre y activo. Allí, la libertad de acción es mediada por la expresión colectiva de la sociedad. Ahora bien, para que pueda formarse a un sujeto autónomo y reflexivo se requiere un contexto que admita este tipo de intervención y el espacio que puede brindar esta posibilidad es el de la democracia.

La democracia es definida por los estudiantes como "el derecho y el deber de los ciudadanos a opinar sobre el futuro de su ciudad o país. Es el derecho de cada individuo para corroborar los intereses colectivos y particulares. Facultad de la ciudadanía para participar activamente en decisiones de su comunidad que tengan relación con el interés general. Es la forma en que los ciudadanos aportan sus opiniones frente a problemas que presenta el Estado. Tener en cuenta a la ciudadanía en las decisiones de gobierno. Es la inclusión de los habitantes de un municipio en las decisiones importantes del mismo, este es un derecho" (estudiantes entrevistados). 74 de los encuestados relacionan la categoría participación con la democracia:

Se ha dicho que la democracia es poder popular. Al respecto, Giovanni Sartori concluye:

Si esto es así - y este es el argumento — las democracias deben ser lo que dice la palabra: sistemas y regímenes políticos en los que el pueblo manda. ¿Todo lo que se ha dicho está resuelto? No. En tanto, ¿quién es el pueblo? Y luego, ¿cómo atribuir poder al pueblo? ¿Cómo hacer eso?21

Por otra parte, se ha planteado que el rastreo de las concepciones de participación se enmarca en el modelo de la democracia participativa. Sin embargo, los datos indican una amalgama de varias

20 Will Kymlicka, La política vernácula, nacionalismo, multiculturalismo y ciudadanía, 32 (Paidós, Barcelona, 2003).

21 Giovanni SARTori, ¿Qué es la democracia?, 7 (Altamir, Bogotá, 1994). 
concepciones sobre la democracia para definir la participación, como se observa a continuación:

"La participación ciudadana es un mecanismo para materializar el concepto de democracia, o sea, es un mecanismo que busca que los ciudadanos participen activamente y se involucren en la toma de decisiones relevantes para el pueblo" (entrevista con estudiante). Sartori, por su parte, sostiene que "El pueblo comienza desde el demos de los griegos. Y del demos había, ya en el siglo V a.C. muchas interpretaciones. Por ejemplo, para Aristóteles el demos expresaba a los pobres". Para los estudiantes, es "el derecho que tiene la ciudadanía en la elección de sus gobernantes, como Estado democrático que es Colombia".

El sentido de democracia en las respuestas de los estudiantes es la pluralidad y la multiculturalidad: "Es la voz del pueblo en los asuntos que conciernen a nuestro país sea cual fuere su naturaleza. Es la vocería del pueblo para dar a conocer su situación del y en el pueblo, dando a conocer su situación de vivencia" (entrevista con estudiante).

Y es, por otra parte, lo que teóricamente se expresa en la Constitución de 1991: "Colombia es un Estado social de Derecho... democrática, participativa y pluralista" ${ }^{22}$. El ingreso del pluralismo en la Constitución dota a Colombia de un concepto de democracia diametralmente distinto al concebido en la Constitución de 1886, y es la promesa del reconocimiento de las múltiples culturas que habitan el territorio.

La categoría democracia se relaciona con las de principio y fin de la CP de 1991. En concordancia con el preámbulo, el artículo 1 de la CP dice así:

Colombia es un Estado social de Derecho, organizado en forma de República unitaria, descentralizada, con autonomía de sus entidades territoriales, democrática, participativa y pluralista, fundada en el respeto de la dignidad humana, en el trabajo y la solidaridad de las personas que la integran y en la prevalencia del interés general ${ }^{23}$.

Este texto constitucional caracteriza a Colombia como Estado social de derecho, lo que implica una transformación radical del

22 Colombia, Constitución Política, Bogotá (1991). Disponible en: http://www.alcaldiabogota. gov.co/sisjur/normas/Norma1.jsp?i=4125

23 Colombia, Constitución Política, Bogotá (1991). Disponible en: http://www.alcaldiabogota. gov.co/sisjur/normas/Norma1.jsp?i=4125 
sistema jurídico-político vigente hasta entonces y que define al Estado colombiano según los ideales del "Estado de bienestar". En esta forma, se establecen las características de la república como democrática, pluralista y participativa, por lo cual la participación constituye la piedra angular de la estructura política colombiana. $Y$ de estos principios se deriva que la soberanía reside en el pueblo, y no en la Nación, como lo postulaba la Constitución de 1886.

La Constitución de 1991 define el Estado como democrático cuando asume la soberanía popular como base de todo sistema institucional, según lo expresa el artículo citado. Esto implica la separación de los poderes ejecutivo, legislativo y judicial, complementado por organismos de control electoral y un ministerio público que garantiza la defensa de los derechos ciudadanos. Además, en virtud del principio democrático, cuenta con mecanismos de participación de los ciudadanos, como el voto, el referendo, el plebiscito, la consulta popular, las acciones de grupo y en este sentido, la Ley 134 de $1994^{24}$ la dotó de suficientes mecanismos de participación para la defensa de los derechos de los ciudadanos.

Colombia asume la soberanía popular como base del sistema institucional y combina la democracia representativa con mecanismos de democracia directa y permite la participación de los sujetos en instancias sociales, políticas e institucionales:

En conjunto, es lo que se ha convenido en llamar la democracia participativa, pretendiendo con ello destacar la apertura del Estado y de sus instituciones a la participación de la sociedad civil. En este preciso sentido, la Constitución de 1991 es democrática y moderna ${ }^{25}$.

Luis Tapia-Mealla propone que "la democracia es una de las configuraciones de lo político. En tanto construcción social y epocal de la política ha sido inventada de un modo en Grecia y ha sido reconstituida de otro en tiempos modernos" ${ }^{26}$. De esta manera, la conceptualización de la democracia participativa en Colombia

24 Ley 134 de 1994, por la cual se dictan normas sobre mecanismos de participación ciudadana. Disponible en: http://www.alcaldiabogota.gov.co/sisjur/normas/Normal.jsp?i=330

25 Pedro Santana, La democracia: un proyecto en construcción, 16 (Caja de Herramientas, Bogotá, 1995).

26 Luis Tapia-Mealla, La velocidad del pluralismo. Ensayo sobre tiempo y democracia, 37 (Muela del Diablo Editores, La Paz, 2002). 
corresponde a una construcción social e histórica en que, como Estado, configuramos una forma de organización en la cual sea posible comprendernos, y esa construcción nace de la pluralidad, la diferencia y la diversidad.

Desde el punto de vista político, la participación como acción y como reflexión y dentro del marco de la democracia, implica igualdad y libertad, de modo que la participación puede considerarse como una respuesta a la permanente exclusión de distintos sectores de la población, que ha sido una característica del sistema político colombiano hasta 1991:

Los iguales son los incluidos, los disímiles son excluidos. Las democracias que han existido han acompañado, hasta hoy, los círculos de inclusión con otros de exclusión. Los antiguos los organizaron en torno a la esclavitud, el género $y$ la polis, es decir, la pertenencia de origen. Los modernos en torno al Estado nacional, la clase social, el género, la raza y las generaciones también ${ }^{27}$.

En Colombia, la configuración del Estado se ha basado en la discriminación social patológica de las instituciones nacionales, de corte elitista y clientelista. Como reacción a este carácter excluyente, puede entenderse la participación como principio de inclusión a partir del reconocimiento de las personas como ciudadanos y sujetos de derecho. Esto permite la conformación de una sociedad heterogénea que abra espacios de acceso a todos los ciudadanos para la construcción, ejecución y evaluación de las políticas públicas. En palabras de Boaventura de Sousa Santos,

Por primera vez en la historia, la igualdad, la libertad y la ciudadanía son reconocidas como principios emancipatorios de la vida social. La desigualdad y la exclusión tienen entonces que ser justificadas como incidentes de un proceso social que en principio no les reconoce legitimidad alguna. Y frente a ellas, la única política social legítima es aquella que define los medios para minimizar una y otra ${ }^{28}$.

Del mismo modo que la ciudadanía y que los procesos de igualdad y de inclusión, la participación es una posibilidad para contra-

27 Luis Tapia-Mealla, La velocidad del pluralismo. Ensayo sobre tiempo y democracia, 38 (Muela del Diablo Editores, La Paz, 2002).

28 Boaventura de Sousa Santos, El milenio huérfano, ensayos para una nueva política, 195 (Trotta, Bogotá, 2005). 
rrestar el conflicto social puesto que, como principio constitucional, admite la heterogeneidad de quienes participan, de modo que en el control del espacio público se podrán encontrar los desiguales y los excluidos:

La desigualdad y la exclusión son dos sistemas de pertenencia jerarquizada. En el sistema de desigualdad, la pertenencia se da por la integración subordinada, mientras que en el sistema de exclusión la pertenencia se da por la exclusión. Quien se encuentra abajo está adentro y su presencia es indispensable ${ }^{29}$.

El reconocimiento de la heterogeneidad como una característica de la sociedad implica comprenderla como un espacio conflictivo, en el que se presentan contradicciones de personalidades, intereses y culturas. A partir de esta base, la participación es una respuesta generalizada, es decir, dirigida a todas las personas, con énfasis en la diferencia, según las posibilidades de cada una. En esta forma:

La democracia se inventa como un modo de vida política que problematiza a la vez la desigualdad socioeconómica y la desigualdad política. La democracia no es solo una forma de gobierno y un conjunto de instituciones sino un movimiento problematizador de las desigualdades ${ }^{30}$.

Consecuente con la participación como principio, la democratización del poder político considera posibilidades de incidencia real de los ciudadanos y de sus organizaciones sociales en las decisiones del Estado. La orientación y la protección de los intereses públicos no recaen solamente en los funcionarios y las instituciones del Estado, sino que se admite la concurrencia de los ciudadanos. Este criterio adquiere importancia porque establece el sentido de la corresponsabilidad o responsabilidad compartida entre el Estado y la sociedad.

La participación no necesita la mediación de la institucionalidad estatal. Por el contrario, se dan múltiples y variadas expresiones participativas, verificables en escenarios alternativos y no institucionalizados, de manera que la oferta de participación de las enti-

29 Luis Tapia-Mealla, La velocidad del pluralismo. Ensayo sobre tiempo y democracia, 38 (Muela del Diablo Editores, La Paz, 2002).

30 Luis Tapia-Mealla, La velocidad del pluralismo. Ensayo sobre tiempo y democracia, 63 (Muela del Diablo Editores, La Paz, 2002). 
dades adopta formas grupales, desde el punto de vista territorial y sectorial, y se presta real atención a las experiencias locales.

A pesar de que las implementaciones prácticas de la participación no se han evidenciado en estos más de veinte años en el derecho civil, varios artículos indirectamente plantean el derecho a la participación, para el acceso a estos derechos según el artículo 64 de la Constitución que plantea la posibilidad de que las personas puedan tener acceso a la tierra en forma individual o asociativa.

El ideal planteado arriba se plasma en los currículos de los programas de derecho, clasificados en este trabajo como currículo activo y currículo integral, y que se plantean en sus misiones, visiones y objetivos: "Formar profesionales en el área del Derecho y la Ciencia Política, con capacidad de acción y reflexión sobre el contexto social nacional e internacional"31. Hay allí una preocupación por la actuación reflexiva del sujeto que aprende para transformar su entorno social. Y esta es una búsqueda que, conceptualizada de diferentes maneras, realizan los programas de derecho: lograr una transformación de su entorno local o nacional: "Que con la acertada aplicación de su conocimiento en la ciencia del derecho, contribuyan al desarrollo de la región..." ${ }^{32}$, de acuerdo con la teoría de la acción social, ¿cómo formar profesionales del derecho que respondan individual y colectivamente a las necesidades de su medio? Los currículos estudiados hacen una apuesta por la investigación, que corresponde a la regulación estatal de los contenidos de los procesos de formación en derecho.

No puede entonces quedarse la investigación como una mera propuesta normativa para los currículos, pues es necesario volver a ella como mediadora en la formación del sujeto que requiere la sociedad colombiana. No hacerlo es dejarla ${ }^{33}$ como un discurso sin sujeto, en el cual la persona no importa, porque lo verdaderamente importante son las leyes históricas implacables en su lógica de funcionamiento. Por lo tanto, no contaba y esto llevó a muchos a construir un discurso brillante, pero sin responsable.

31 Misión del programa de Derecho de la Universidad Nacional de Colombia. http://www. derecho.unal.edu.co/vicedecanatura_academica.html

32 Misión del programa de Derecho de la Universidad de la Amazonía. http://www.uniamazonia. edu.co/v10/index.php/facultades/facultad-de-derecho-y-ciencias-politicas.html

33 Hugo Zemelman, Pensamiento crítico y neoliberalismo en América Latina (Universidad Pedagógica Nacional, Bogotá, 2010). 
Se requieren diversas apuestas en el proceso de formación, entre ellas la de una identificación del fin para el que se forma y ello implica un reconocimiento del contexto respecto a la estructura social. Los abogados se forman dentro del marco social, económico y político del país, y esto requiere reconocer que hay una Carta constitucional que guíe y regule la interacción, pues aparte de la Constitución, el Estado se ha erigido durante más de quinientos años en formas de organización cultural, diversidad y pluralismo propias de la hibridación de culturas que lo constituyen y estos entrecruzamientos definen diversas formas de organización, de resolución de problemas y de establecimiento de conflictos de toda índole, que evidencian pluralismo, diversidad, multiculturalidad y ello implica diversas visiones del mundo y de comprensión de la realidad.

Lo segundo que se debe tener en cuenta es que la formación debe tocar la conciencia del sujeto con el fin de que se cumpla el interés planteado en las misiones de lograr la transformación del entorno. En este sentido, la acción, en términos de Max Weber:

En especial la social y también singularmente la relación social, pueden orientarse, por el lado de sus partícipes, en la representación de la existencia de un orden legítimo. La probabilidad de que esto ocurra de hecho se llama "validez" del orden en cuestión ${ }^{34}$.

La acción que se propone en algunos proyectos educativos institucionales, PEI, de los programas de derecho tendría que estar encaminada al reconocimiento de este orden que trata Max Weber respecto a que la validez es el respeto por la regulación de la interacción social. Esto estaría conectado con el para qué de su acción. Es importante entonces, esa iniciativa para que ocurra algo que derive en nuevas construcciones sociales, y esto debe alcanzarse por medio del proceso de formación. Es el sentido que Cornelius Castoriadis ${ }^{35}$ sugiere como una paideia democrática que produzca sujetos preparados para la acción que resuene en el conjunto social. En esta forma, se afectarían los currículos de los programas, cuyo propósito es la formación de un sujeto político, lo que expresa la

34 Max Weber, Economía y Sociedad, 79 (Fondo de Cultura Económica, FCE, México, 1944).

35 Cornelius Castoriadis, La democracia como procedimiento y como régimen, 38 Iniciativa Socialista (1996). Disponible en: http://www.inisoc.org/Castor.htm 
preocupación de los programas por lo político como parte de la formación de los estudiantes, puesto que el derecho en Colombia como expresión de la sociedad, refleja las condiciones sociales, económicas y políticas del país.

En la politica se constituyen sujetos. Algunos son constituidos heterónomamente. Otros se autoconstituyen con mayor grado de autonomía. Incluso en los casos de constitución vertical, siempre hay una dimensión subjetiva que acaba aceptando la interpelación autoritaria y, así, acaba produciendo la relación de subordinación a través de la cual se constituye el sujeto. La política es un campo de fuerzas en el que los sujetos crean instituciones, pero también en el que las pueden destruir, reformar, sustituir ${ }^{36}$.

En esta investigación, el derecho, promulgado por la Constitución Política y desarrollado en las áreas normativas que rigen en Colombia, debe expresarse en el comportamiento social y político de los ciudadanos. La intención de los currículos es la posibilidad de incidir en las prácticas de los profesionales del derecho, lo que repercute en la vida política nacional. Sin embargo, algo dentro de lo planteado en los currículos no suena a verdad, hay una preocupación por plasmar un discurso convincente pero que no logra realizaciones en la práctica, como señala Nieves Blanco-García:

Que en tiempos de conflictos entre diferentes concepciones de la sociedad (y por ende de la escuela y el conocimiento que ha de transmitir) el Estado cae con sospechosa frecuencia en la tentación de utilizar la educación como un campo de legitimación (y a los expertos y a los ciudadanos para garantizarla ${ }^{37}$.

Si la política es ese espacio de construcción de las relaciones sociales, dentro de las cuales los sujetos se autorregulan, construyen y deconstruyen sus formas de convivencia, tal como lo plantea Tapia, "en la política experimentamos tanto el poder de la creación como el de la deconstrucción de lo social y las condiciones que este ha producido para reproducirse, ampliarse, renovarse" 38 . El derecho debe ser parte de esa construcción social en el ejercicio evolutivo de acomodación que requiere la sociedad.

36 Luis Tapia-Mealla, Política salvaje, 111 (Muela del Diablo Editores, La Paz, 2008).

37 Nieves Blanco-García, El sentido del conocimiento escolar (notas para una agenda de trabajo), en Volver a pensar la educación, Congreso Internacional de Didáctica, vol. I, Política, Educación y Sociedad, 188-202, 195 (Morata, Madrid, 1999).

38 Luis Tapia-Mealla, Política salvaje, 111 (Muela del Diablo Editores, La Paz, 2008). 
La participación como utopía se encuentra en el contenido de estas categorías que constituyen tal concepción y en los datos emanados de los instrumentos con los cuales se realizó la aproximación empírica. La participación se erige como un ideal de pluralidad, de libertad, de igualdad en el Estado social de derecho. Sin embargo, las categorías constituyentes no tienen fuerza suficiente para darle vida a una participación con estas características. Los estudiantes aclararon que estas argumentaciones son ideales de la participación. 


\section{CONCLUSIONES}

A continuación, se presentan las conclusiones del estudio relacionadas con los hallazgos y desarrollos de los capítulos provenientes de las preguntas orientadoras y de los objetivos de la investigación confrontados con los datos.

- Como se señaló en los capítulos que presentan las concepciones de participación de los estudiantes de derecho en Colombia, categorías como derecho fundamental, libertad, reflexividad y metaderecho permitieron sustentar concepciones sobre la participación, pues definen la práctica social del Estado social de derecho y el desarrollo del sujeto estudiante de leyes como ciudadano impecable. Sin embargo, llama la atención que junto a muchos conceptos sobre participación expresados por ellos aparecen entre paréntesis palabras como "utopía", "farsa", "esto no se da", "en Colombia no existe". Con ello se expresa que la participación ciudadana es un concepto que se ha venido tratando de manera teórica y no se relaciona con la realidad del país, aunque ingresa en los discursos de los estudiantes.

- Estas calificaciones que los estudiantes hacen de los conceptos que emiten también dejan ver que esos conceptos tienen cabida en sus expectativas y su sistematización mental, pero descalificarlas como farsa indica que no ven una coherencia entre lo que se dice y lo que se hace, entre lo que está escrito en la Constitución y la realidad social. Este es obstáculo para la construcción del Estado social de derecho que erige la participación de los ciudadanos como principio democrático. Expresan así los estudiantes el mismo desencanto de Gabriel García-Márquez cuando decía que "en los colombianos cohabitan la justicia y la impunidad; somos fanáticos del legalismo, pero llevamos bien despierto en el alma un leguleyo de mano maestra para burlar las leyes sin violarlas o para violarlas sin castigo" 39 .

- La formación de los estudiantes de derecho en Colombia está influenciada por las dinámicas de educación del siglo XX. Boa-

39 Gabriel García-Márquez, Por un país al alcance de los niños, discurso pronunciado durante la ceremonia de entrega del informe de la Misión de Ciencia, Educación y Desarrollo, publicado en El Espectador, sábado 23 de julio de 1994. Disponible en: http://www.scp.com.co/ ArchivosSCP/Por_un_pais.pdf, citado por Mauricio García-Villegas, dir., Normas de papel, la cultura del incumplimiento de reglas de justicia, 20, Siglo del Hombre Editores, Bogotá (2009). 
ventura de Sousa Santos y Mauricio García-Villegas se refieren así a la formación en educación superior:

fue un conocimiento eminentemente disciplinar, cuya autonomía impuso un proceso de producción relativamente descontextualizado con relación a las necesidades del mundo cotidiano de las sociedades ${ }^{40}$.

- Los currículos de los programas de Derecho estudiados están elaborados con los elementos normativos dictados por el Ministerio de Educación. Su organización es teóricamente completa porque desarrolla los objetivos, propósitos y perfiles adecuados a los lineamientos normativos del país. Sin embargo, si se tienen en cuenta las concepciones de participación de los estudiantes encuestados, estos no se forman en coherencia con tales discursos lo que se revela en sus opiniones, sus conceptos y sus prácticas universitarias. Tal como lo afirma Nelcy López-Cuéllar:

la técnica pedagógica más usada en las aulas de derecho fue para los entrevistados la cátedra magistral, marcada por un monopolio del saber en cabeza del profesor y una jerarquia inferior del alumno a quien le correspondia escuchar a quien enseñaba (45, 47, 88). Finalmente, en La profesión se evidencia que la investigación brilló por su ausencia en la educación de algunos entrevistados ${ }^{4 l}$.

- Desde la Constitución de 1991, se viene hablando de una formación que se contextualice con las necesidades sociales, más humana, ubicada en la realidad. Desde el preámbulo de la Carta Fundamental, se ha destacado el valor de la educación al consagrar como elementos que caracterizan el Estado Social de Derecho, la igualdad y el "conocimiento", cuyos bienes consolidan la estructura de un marco jurídico que garantice un orden político, económico y social justo, en función de la prevalencia del interés general. Para ello, es necesario contar con la comunidad:

El papel del ciudadano común es indispensable en el momento de construir las instituciones y los valores colectivos. Nuestros significantes deben ser el

40 Boaventura de Sousa Santos \& Mauricio García-Villegas, El caleidoscopio de las justicias en Colombia, 34 (Siglo del Hombre Editores, Universidad de Los Andes, Bogotá, 2001).

41 Nelcy López-Cuéllar, Un paso adelante en investigación cualitativa en el área de la enseñanza del Derecho en Colombia. Reseña de "La profesión va por dentro" de Pedro Javier López (Universidad del Rosario, Colección Nova, Bogotá, 2010, 290 p.), 123 Vniversitas, 441-452 (2011). Disponible en: http://www.scielo.org.co/pdf/vniv/n123/n123a15.pdf 
resultado de una construcción colectiva, participativa y culturalmente autorreferenciada. La apuesta está en que podemos crear a partir de nuestras propias experiencias sociales ${ }^{42}$.

- Las concepciones de participación de los estudiantes de Derecho en Colombia están signadas por características de hibridaciones conceptuales, influidas por la formación teórica que reciben por medio de sus procesos curriculares, que los confronta con una realidad que no coincide con lo que están aprendiendo. Parte de la crisis en los procesos de formación radica en su estandarización. No se requiere una formación en el derecho, sino de una formación plural en el derecho.

- Es necesario que los procesos de formación de los estudiantes de derecho se miren en las ciencias sociales, entre las cuales se ubica el derecho, pues históricamente ha estado también influido por el desarrollo de las posturas positivistas, históricas, estructuralistas, críticas, sociales, complejas, pues es una disciplina que necesita de todas las demás para constituirse, comprenderse y alcanzar sus objetivos de regulación social.

- En consonancia con una formación en derecho mediante la pedagogía crítica es necesario conjugar las prácticas de los estudiantes con los procesos de aprendizaje, como escenario del ejercicio de la ciudadanía. Ello no es posible mientras la formación se siga dando en los espacios cerrados de cuatro paredes y en la lógica individualista de formación. Se requiere una formación autorregulada y flexible en el proceso de aprendizajes orientados por los estudiantes (autonomía), trabajo colaborativo (grupos de discusión, de investigación, de prácticas).

42 Diana Durán-Smela, Entre el republicanismo y el constitucionalismo popular. ¿Cómo potenciar la participación democrática en la construcción de la política pública y constitucional del bien común?, 123 Vniversitas, 169-202, 176 (2011). Disponible en: http://www.scielo.org.co/pdf/vniv/ n123/n123a07.pdf 


\section{BIBLIOGRAFÍA}

\section{Libros}

Arendt, Hannah, La condición humana (Paidós, Barcelona, 1993).

Bobbio, Nor berto, Igualdad y Libertad (Paidós y el Instituto de Ciencias de la Educación, ICE, de la Universidad Autonóma de Barcelona, UAB, Barcelona, 1993).

Bobbio, Norberto, Liberalismo y democracia (México D.F., Fondo de Cultura Económica, colección Breviarios FCE, 1989).

García-Villegas, Mauricio, dir., Normas de papel, la cultura del incumplimiento de reglas de justicia (Siglo del Hombre Editores, Bogotá, 2009).

Kymlicka, Will, La política vernácula, nacionalismo, multiculturalismo y ciudadanía (Paidós, Barcelona, 2003).

Luckmann, Thomas, Teoría de la acción social (Paidós Ibérica, Barcelona, 1996).

Mardones, José María, Filosofía de las ciencias humanas y sociales. Materiales para una fundamentación científica (Anthropos, Barcelona, 1991).

Santana, Pedro, La democracia: un proyecto en construcción (Caja de Herramientas, Bogotá, 1995).

Santos, Boaventura de Sousa, El milenio huérfano, ensayos para una nueva política (Trotta, Bogotá, 2005)

Santos, Boaventura de Sousa, \& García-Villegas, Mauricio, El caleidoscopio de las justicias en Colombia (Siglo del Hombre Editores, Universidad de Los Andes, Bogotá, 2001).

SARtori, Giovanni, ¿Qué es la democracia? (Altamir, Bogotá, 1994).

Sen, Amartya K., Desarrollo y libertad (Planeta, Barcelona, 2000).

Tapia-Mealla, Luis, La velocidad del pluralismo. Ensayo sobre tiempo y democracia (Muela del Diablo Editores, La Paz, 2002).

Tapia-Mealla, Luis, Política salvaje (Muela del Diablo Editores, La Paz, 2008).

Thiebaut, Carlos, Vindicación del ciudadano, un sujeto reflexivo en una sociedad compleja (Paidós, Barcelona, 1998).

Weber, Max, Economía y Sociedad (Fondo de Cultura Económica, FCE, México, 1944).

\section{Colaboración en obras colectivas}

Aвramovich, Víctor E., La enseñanza del derecho en las clínicas legales de interés público: materiales para una agenda temática, en Defensa Jurídica del Interés Público, Enseñanza, estrategias, experiencias, 61-94 (Universidad Diego Portales, Santiago de Chile, 1999). Disponible en: http://www.udp.cl/descargas/facultades_carreras/ derecho/pdf/investigaciones/Cuadernos_de_analisis_Coleccion_Derecho_ Privado/especiales/CAJ_n09_Serie_Publicaciones_Especiales.pdf, http://www. 
palermo.edu/derecho/pdf/Bibliografia-clinicas-juridicas/la_ensenanza_del_ derecho_en_las_clinicas_legales_de_interes_publico $\% 282 \% 29 . p d f$

BlanCo-García, Nieves, El sentido del conocimiento escolar (notas para una agenda de trabajo), en Volver a pensar la educación, Congreso Internacional de Didáctica, vol. I, Política, Educación y Sociedad, 188-202 (Morata, Madrid, 1999).

BöHMer, MARTIN, Introducción, en La enseñanza del derecho y el ejercicio de la abogacía, 13-23 (Martin Böhmer, comp., Gedisa, Barcelona, 1999).

Droysen, Johann Gustav, Grundriss der historik, en Die Erklären: Verstehen Kontroverse in Transzendental Pragmatischer Sicht (KARL OtTo APEL, Frankfurt, Suhrkamp, 1858).

\section{Revistas}

Amsterdam, Anthony G., Clinical Legal Education, A 21 $1^{\text {st }}$ Century Perspective, 34 Journal of Legal Education, 4, 612-618 (1984).

Ángel-Pérez, Darío Alberto \& Herrera, José Darío, La propuesta hermenéutica como crítica y como criterio del problema del método, 43 Estudios de Filosofía, 9-29 (2011). Disponible en: http://aprendeenlinea.udea.edu.co/revistas/index.php/ estudios_de_filosofia/article/viewFile/11565/10543

CASTORIADIS, CORnelius, La democracia como procedimiento y como régimen, 38 Iniciativa Socialista, en línea (1996). Disponible en: http://www.inisoc.org/Castor.htm

DurÁn-Smela, Diana, Entre el republicanismo y el constitucionalismo popular. ¿Cómo potenciar la participación democrática en la construcción de la política pública y constitucional del bien común?, 123 Vniversitas, 169-202 (2011). Disponible en: http://www.scielo.org.co/pdf/vniv/n123/n123a07.pdf

López-Cuéllar, Nelcy, Un paso adelante en investigación cualitativa en el área de la enseñanza del Derecho en Colombia. Reseña de "La profesión va por dentro" de Pedro Javier López (Universidad del Rosario, Colección Nova, Bogotá, 2010, 290 p.), 123 Vniversitas, 441-452 (2011). Disponible en: http://www.scielo.org.co/pdf/ vniv/n123/n123a15.pdf

Plessis, Alain, Histoire bancaire et prosopographie, 9 Bulletin des liaison des sociétés savantes, 3-4 (mars 2004). Disponible en: http://cths.fr/_files/an/pdf/bulletin9.pdf

Vargas-Bejarano, Julio César, El concepto de acción politica en el pensamiento de Hannah Arendt, 11 Eidos, Revista de Filosofia de la Universidad del Norte, 82107 (2009). Disponible en: http://www.redalyc.org/articulo.oa?id=85412265004

\section{Discursos, ponencias, resúmenes, tesis}

Bianchetti, Alba Esther de; Fridman, Susana Alejandra \& Zárate, Hilda Zulema, La evaluación del proceso enseñanza-aprendizaje del derecho (Resumen S-008, en línea, Universidad Nacional del Nordeste, Corrientes, 2003). Disponible en: http://www.unne.edu.ar/unnevieja/Web/cyt/cyt/2003/comunicaciones/01Sociales/S-008.pdf 
CAstellanos-Obregón, JuAn Manuel, Formas actuales de la movilización armada: una aproximación prosopográfica, Tesis de doctorado en ciencias sociales, niñez y juventud, Centro de Estudios Avanzados en Niñez y Juventud, CEANJ, Universidad de Manizales, Centro Internacional de Educación, CINDE (2009). Disponible en: http://biblioteca.clacso.edu.ar/Colombia/alianza-cindeumz/20130225065635/juanmanuelcast.pdf

García-Márquez, Gabriel, Por un país al alcance de los niños, discurso pronunciado durante la ceremonia de entrega del informe de la Misión de Ciencia, Educación y Desarrollo, publicado en El Espectador, sábado 23 de julio de 1994. Disponible en: http://www.scp.com.co/ArchivosSCP/Por_un_pais.pdf

Zemelman, Hugo, Pensamiento crítico y neoliberalismo en América Latina, Ponencia Universidad Pedagógica Nacional, Bogotá (2010).

\section{Normatividad colombiana}

Colombia, Constitución Política, Bogotá (1991). Disponible en: http://www. alcaldiabogota.gov.co/sisjur/normas/Norma1.jsp?i=4125

Ley 134 de 1994, por la cual se dictan normas sobre mecanismos de participación ciudadana. Disponible en: http://www.alcaldiabogota.gov.co/sisjur/normas/ Norma1.jsp?i=330

\section{Direcciones web}

Misión del programa de Derecho de la Universidad Nacional de Colombia. http://www. derecho.unal.edu.co/vicedecanatura_academica.html

Misión del programa de Derecho de la Universidad de la Amazonía. http://www. uniamazonia.edu.co/v10/index.php/facultades/facultad-de-derecho-y-cienciaspoliticas.html 
